Check for updates

Cite this: Chem. Sci., 2019, 10, 7887

๑ All publication charges for this article have been paid for by the Royal Society of Chemistry

\section{Observation of osmotically driven, highly controllable and reconfigurable oil/water phase separation $\dagger$}

\author{
Ning Gao, Jiecheng Cui, \$Wanlin Zhang, Kai Feng, Yun Liang, Shiqiang Wang, \\ Peng Wang, Kang Zhou and Guangtao Li (iD *
}

Liquid-liquid phase separation has been proven to be a valuable method for producing structured materials and creating chemical systems. Although several strategies have been developed to date, osmotically driven oil/water phase separation has never been achieved owing to the limited solubility of inorganic salts in conventional organic solvents and thus the insufficient osmotic driving force to counterbalance the Laplace pressure associated with the interfacial tension. Herein, we report the discovery that a mixture of 1-alkyl-3-vinylimidazolium bis(trifluoromethanesulfonyl)imide and $\mathrm{LiTf}_{2} \mathrm{~N}$ can generate sufficient and widely tunable osmotic pressure in oil to realize water transport from the surrounding aqueous phase into the oil phase, triggering spontaneous phase separation. This osmotically driven phase separation could be modulated with unprecedented flexibility, offering unlimited possibilities to facilely access diverse thermodynamically metastable structures using one system. Importantly, this oil system can serve as a general phase separation carrier platform for realizing phase separation of various substances.
Received 3rd April 2019

Accepted 21st June 2019

DOI: $10.1039 / c 9 s c 01649$ j

rsc.li/chemical-science shrinking) of aqueous phases without any phase transition. ${ }^{17-19}$ As conventional organic oils have limited solubility of the osmolyte (e.g. inorganic salts) and thus the generated osmotic pressure cannot counterbalance the Laplace pressure induced by water uptake, ${ }^{20,21}$ to the best of our knowledge, osmotically driven phase separation in common homogeneous oil phases has never been observed.

Ionic liquids (ILs) are a class of molten salts consisting of organic cations and anions, and are often viewed as an "intermediate" between organic molecular liquids and molten salts. ${ }^{22-24}$ Stemming from their dual ionic and organic nature, ionic liquids (ILs) exhibit a series of unique physicochemical properties. One of the distinctive properties of ILs is their excellent solvency for a broad range of substances. ${ }^{25,26}$ Compared with normal organic solvents hydrophobic ILs can even display peculiar solubility for different inorganic salts to form homogeneous oil solutions. ${ }^{27-30}$ In this work, we report the discovery that one of such special oil solutions, namely the mixture $\left(\mathrm{C}_{n} \operatorname{vim}\left[\mathrm{Tf}_{2} \mathrm{~N}\right]-\mathrm{LiTf}_{2} \mathrm{~N}\right)$ of 1-alkyl-3-vinylimidazolium bis(trifluoromethanesulfonyl)imide $\left(\mathrm{C}_{n} \operatorname{vim}\left[\mathrm{Tf}_{2} \mathrm{~N}\right]\right)$ and $\operatorname{LiTf}_{2} \mathrm{~N}$, can generate sufficient and widely tunable osmotic pressure in oil to realize water transport from the surrounding aqueous phase into the oil phase. Completely different from osmotically driven water flow in common emulsion systems reported so far, in which mass transport only occurs between two aqueous phases, the osmotically driven water transport described here from the aqueous phase into the oil phase can trigger spontaneous oil/water phase separation. It was found that the
Department of Chemistry, Key Lab of Organic Optoelectronics and Molecular Engineering, Tsinghua University, Beijing 100084, P. R. China. E-mail: lgt@mail. tsinghua.edu.cn

$\dagger$ Electronic supplementary information (ESI) available. See DOI: 10.1039/c9sc01649j

\$ These authors contributed equally to this work. 
thermodynamic driving force, kinetic barrier and direction of this osmotically driven phase separation (OPS) could be facilely modulated with unprecedented flexibility by varying the amount of $\operatorname{LiTf}_{2} \mathrm{~N}$ dissolved in $\mathrm{C}_{n} \operatorname{vim}\left[\mathrm{Tf}_{2} \mathrm{~N}\right]$, changing the molecular structure of $\mathrm{C}_{n} \operatorname{vim}\left[\mathrm{Tf}_{2} \mathrm{~N}\right]$ and altering the salt concentration in the aqueous phase. Surprisingly, by adding salt into the aqueous phase, the already phase-separated heterogeneous state could even be reverted to restore the homogeneous oil phase by redrawing the water molecules that are taken up, indicating that the OPS is reconfigurable. Thus, compared with those of the liquid-liquid phase separation methods reported so far, these attractive attributes enable precise design and control over the speed and kinetic pathways of the phase separation process, which offers unlimited possibilities to facilely access and capture diverse thermodynamically metastable structures using one phase separation system. Complex emulsions with a broad-spectrum of internal structures, including bicontinuous, sea-island, gradient, anisotropic, multicompartmental, and high-order multilayer structures could be easily achieved in a simple single-step OPS using one system, as shown in Fig. 1. Importantly, we found that without a significant change of its phase separation behaviour the extraordinary solubility of ionic liquids towards a broad range of substances allows the $\mathrm{C}_{n} \operatorname{vim}\left[\mathrm{Tf}_{2} \mathrm{~N}\right]-\mathrm{LiTf}_{2} \mathrm{~N}$ system to serve as a general phase separation carrier platform for realizing the phase separation of various substances, especially those inaccessible using conventional methods, providing enormous opportunities to realize the fabrication of various nano- or micro-structured materials with widely tailorable internal structures through a simple one-step phase separation process.

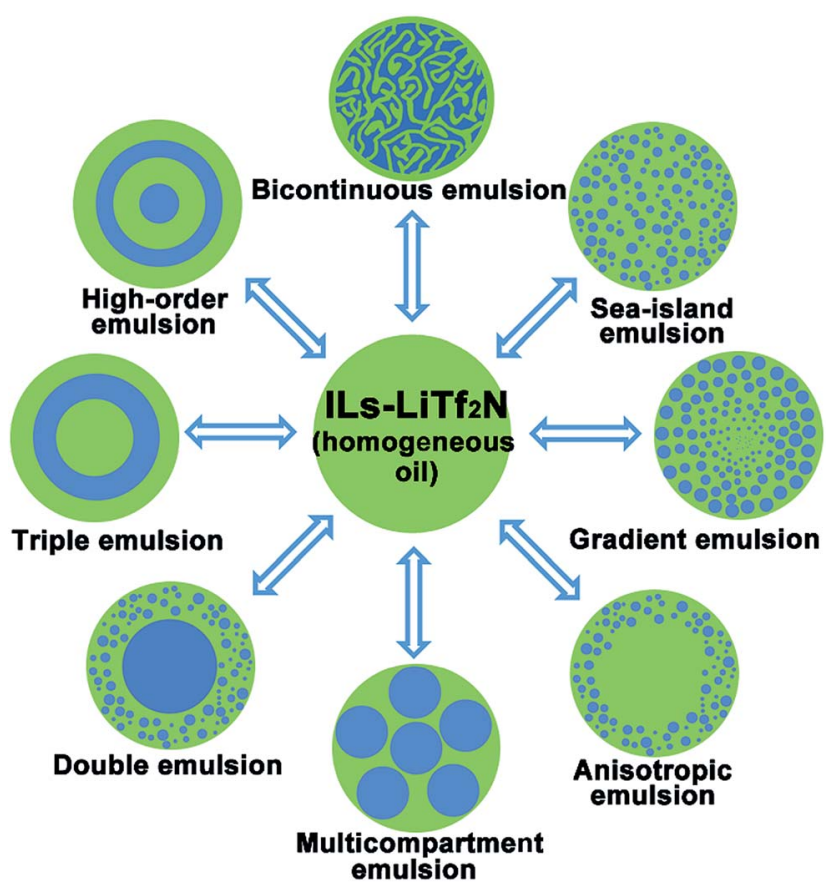

Fig. 1 One-step fabrication of diverse complex emulsion structures by using osmotically driven water-oil phase separation.

\section{Results and discussion}

\section{$\operatorname{LiTf}_{2} \mathbf{N}$ solubility in $\mathrm{C}_{n} \operatorname{vim}\left[\mathrm{Tf}_{2} \mathrm{~N}\right]$ ionic liquids}

Compared to the conventional hydrophobic organic solvents, the unique dual organic and ionic nature of ionic liquids endows them with distinctive solubility of inorganic salts. ${ }^{27-30}$ The dissolved salts in the resultant IL oil solution should provide an osmotic driving force to induce phase separation upon exposure to the aqueous phase. In our case, a series of hydrophobic, low viscosity and polymerizable ionic liquids $\left(\mathrm{C}_{n} \operatorname{vim}\left[\mathrm{Tf}_{2} \mathrm{~N}\right], n=3,6,8,10\right)$ were synthesized (Fig. S1, $\dagger$ the synthesis method and ${ }^{1} \mathrm{H}$ NMR, ${ }^{13} \mathrm{C}$ NMR and mass spectra are described in the ESI $\dagger$ ) and chosen as oil solvents (Fig. 2a), and their solubility towards inorganic salts was first verified. As a demonstration, Fig. 2 b clearly displays the solubility of $\operatorname{LiTf}_{2} \mathrm{~N}$ in $\mathrm{C}_{3} \operatorname{vim}\left[\mathrm{Tf}_{2} \mathrm{~N}\right]$. Pure $\mathrm{C}_{3} \operatorname{vim}\left[\mathrm{Tf}_{2} \mathrm{~N}\right]$ is a pale yellow liquid. When 0.05 molar $\operatorname{LiTf}_{2} \mathrm{~N}$ was added in 1 molar $\mathrm{C}_{3} \operatorname{vim}\left[\mathrm{Tf}_{2} \mathrm{~N}\right]$, the salt was rapidly dissolved and a homogeneous solution is formed. With increasing amounts of $\operatorname{LiTf}_{2} \mathrm{~N}$, even 0.5 molar salt, it is found that in all cases the salts dissolved very well in 1 molar $\mathrm{C}_{3} \operatorname{vim}\left[\mathrm{Tf}_{2} \mathrm{~N}\right]$, affording homogeneous solutions with a transparent appearance (Fig. 2b). Dynamic light scattering (DLS) measurements show that no aggregation was detected in the resulting ionic liquid mixtures (Fig. 2c), definitely confirming that $\operatorname{LiTf}_{2} \mathrm{~N}$ dissolved well in $\mathrm{C}_{3} \operatorname{vim}\left[\mathrm{Tf}_{2} \mathrm{~N}\right]$ at the molecule level. Besides $\mathrm{C}_{3} \operatorname{vim}\left[\mathrm{Tf}_{2} \mathrm{~N}\right]$, a similar dissolution capacity of $\operatorname{LiTf}_{2} \mathrm{~N}$ is also found in the more hydrophobic $\mathrm{C}_{n} \operatorname{vim}\left[\mathrm{Tf}_{2} \mathrm{~N}\right](n=6,8,10)$ cases. It should be noted that the solubility of $\operatorname{LiTf}_{2} \mathrm{~N}$ in $\mathrm{C}_{n} \mathrm{vim}$ $\left[\mathrm{Tf}_{2} \mathrm{~N}\right]\left(1\right.$ molar $\mathrm{C}_{n} \operatorname{vim}\left[\mathrm{Tf}_{2} \mathrm{~N}\right.$ ] dissolving 0.5 molar $\left.\quad \operatorname{LiTf}_{2} \mathrm{~N}\right)$ exceeds the saturated solubility of $\mathrm{NaCl}$ in water $(0.12$ molar $\mathrm{NaCl}$ per mole of $\mathrm{H}_{2} \mathrm{O}$ ). This extraordinary capacity of $\mathrm{C}_{n} \mathrm{vim}$
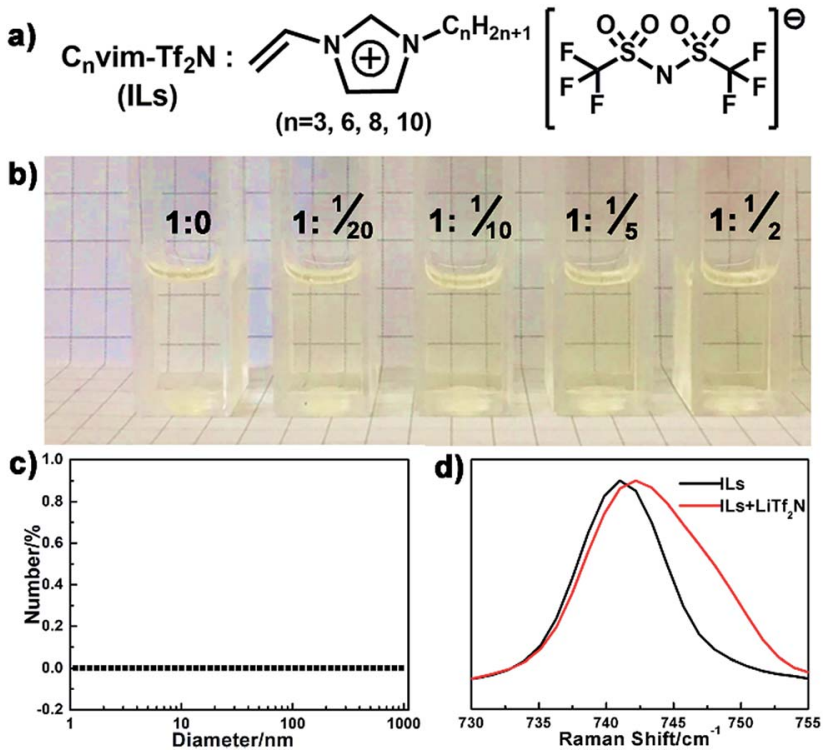

Fig. 2 (a) Chemical structure of the ILs used in this work. (b) Optical images of $\mathrm{C}_{3} \operatorname{vim}\left[\mathrm{Tf}_{2} \mathrm{~N}\right]$ and $\mathrm{LiTf}_{2} \mathrm{~N}$ mixtures with different IL/salt ratios. (c) Dynamic light scattering (DLS) spectrum of the $\mathrm{C}_{3} \operatorname{vim}\left[\mathrm{Tf}_{2} \mathrm{~N}\right]-\mathrm{LiTf}_{2} \mathrm{~N}$ mixture at a molar ratio of $1: 1 / 2$. (d) Raman spectra of neat $\mathrm{C}_{3}$ vim $\left[\mathrm{Tf}_{2} \mathrm{~N}\right]$ and the $\mathrm{C}_{3} \operatorname{vim}\left[\mathrm{Tf}_{2} \mathrm{~N}\right]-\mathrm{LiTf}_{2} \mathrm{~N}(1: 1 / 2)$ mixture. 
$\left[\mathrm{Tf}_{2} \mathrm{~N}\right]$ to dissolve $\operatorname{LiTf}_{2} \mathrm{~N}$ can be attributed to the formation of a four-coordinated structure of the $\mathrm{Li}^{+}$ion of $\mathrm{LiTf}_{2} \mathrm{~N}$ with the $\mathrm{O}$ atoms of two bidentate $\mathrm{Tf}_{2} \mathrm{~N}^{-}$ions of $\mathrm{C}_{n} \operatorname{vim}\left[\mathrm{Tf}_{2} \mathrm{~N}\right] \cdot{ }^{28}$ Fig. $2 \mathrm{~d}$ presents the comparison of the Raman absorption peaks of the $\mathrm{Tf}_{2} \mathrm{~N}^{-}$anion in $\mathrm{C}_{3} \operatorname{vim}\left[\mathrm{Tf}_{2} \mathrm{~N}\right]$ before and after the addition of $\operatorname{LiTf}_{2} \mathrm{~N}$ salt. The intense peak located at $740 \mathrm{~cm}^{-1}$ redshifts to $743 \mathrm{~cm}^{-1}$ in the presence of $\operatorname{LiTf}_{2} \mathrm{~N}$ salt, indicative of the strong interaction between $\mathrm{Li}^{+}$cations and $\mathrm{Tf}_{2} \mathrm{~N}^{-}$anions of $\mathrm{C}_{n}$ vim $\left[\mathrm{Tf}_{2} \mathrm{~N}\right]$, thus demonstrating the dissolution of $\operatorname{LiTf}_{2} \mathrm{~N}$ in $\mathrm{C}_{3}$ vim$\mathrm{Tf}_{2} \mathrm{~N}$. In our work, we also tested the solubility of other types of hydrophobic ILs with their corresponding salts, including $\mathrm{C}_{n} \operatorname{vim}\left[\mathrm{PF}_{6}\right]$ with $\mathrm{LiPF}_{6}, \mathrm{C}_{n} \operatorname{vim}\left[\mathrm{BF}_{4}\right]$ with $\mathrm{LiBF}_{4}$ and $\mathrm{C}_{n} \mathrm{vim}$ $\left[\mathrm{C}_{4} \mathrm{~F}_{9} \mathrm{SO}_{3}\right]$ with $\mathrm{LiC}_{4} \mathrm{~F}_{9} \mathrm{SO}_{3}$. Due to the multiple interactions the $\mathrm{Tf}_{2} \mathrm{~N}^{-}$based ILs $\left(\mathrm{C}_{n} \operatorname{vim}\left[\mathrm{Tf}_{2} \mathrm{~N}\right]\right)$ exhibit the best solubility with their corresponding salts. Thus, the $\mathrm{C}_{n} \operatorname{vim}\left[\mathrm{Tf}_{2} \mathrm{~N}\right]-\mathrm{LiTf}_{2} \mathrm{~N}$ solutions were used as special oil systems for studying their phase separation behaviour.

\section{Osmotically driven phase separation (OPS) of the $\mathrm{C}_{n}$ vim $\left[\mathbf{T f}_{2} \mathbf{N}\right]-$ LiTf $_{2} \mathbf{N}$ system}

Compared to conventional organic hydrophobic solvents, the remarkable amounts of $\operatorname{LiTf}_{2} \mathrm{~N}$ dissolved in $\mathrm{C}_{n} \operatorname{vim}\left[\mathrm{Tf}_{2} \mathrm{~N}\right]$ should provide a sufficient osmotic driving force to induce the phase separation of the $\mathrm{C}_{n} \operatorname{vim}\left[\mathrm{Tf}_{2} \mathrm{~N}\right]$ oil phase when the ionic liquid solution is exposed to an aqueous phase. To efficiently monitor the phase separation behaviour of the $\mathrm{C}_{n} \operatorname{vim}\left[\mathrm{Tf}_{2} \mathrm{~N}\right]$ oil phase, the osmotically driven phase separation (OPS) process was performed in a co-flow microfluidic device in our work. The coflow geometry microfluidic chip used is shown in Fig. S2. $\dagger$ In the microfluidic system, $\mathrm{C}_{n} \operatorname{vim}\left[\mathrm{Tf}_{2} \mathrm{~N}\right]-\operatorname{LiTf}_{2} \mathrm{~N}$ oil was used as the dispersed phase with a flow speed of $0.1-0.3 \mathrm{~mL} \mathrm{~h}^{-1}$ and a $10 \%$ low mW PVA aqueous solution was used as the continuous phase with a flow speed of $5-10 \mathrm{~mL} \mathrm{~h}^{-1}$. This microfluidic approach allows for facilely producing well-defined and uniform oil droplets in a continuous aqueous phase, and thus is beneficial for the capture and observation of kinetic pathways and speed of the OPS process as well as the internal structure evolution of a single droplet as the droplet moves downstream. Additionally, a large-quantity synthesis of uniform materials with well-defined morphologies, including spherical, fibrous and tubular materials, in a short time is another attractive feature of the microfluidic technique (shown in Movie $1 \dagger$ ). ${ }^{31-33}$

Theoretically, when the osmotic driving force provided by the salts dissolved in $\mathrm{C}_{n} \operatorname{vim}\left[\mathrm{Tf}_{2} \mathrm{~N}\right]$ oil exceeds the Laplace pressure associated with the oil/water interface, the water molecules from the continuous aqueous phase would have the capacity to spontaneously diffuse into $\mathrm{C}_{n} \operatorname{vim}\left[\mathrm{Tf}_{2} \mathrm{~N}\right]-\mathrm{LiTf}_{2} \mathrm{~N}$ oil droplets, thus initiating the phase separation process. The Laplace pressure difference $(\Delta P)$ between an oil droplet of radius $R$ and the external aqueous phase resulting from the oil/ water interfacial tension $(\gamma)$ is given by $\Delta P=2 \gamma / R$. When the $\mathrm{C}_{n} \operatorname{vim}\left[\mathrm{Tf}_{2} \mathrm{~N}\right]-\operatorname{LiTf}_{2} \mathrm{~N}$ mixture is simplified as a dilute ideal solution, its osmotic pressure $\Phi$ is $2 c k T$, where $c$ is the concentration of the monovalent salt in the ideal solution. The interfacial tension between the $\mathrm{C}_{n} \operatorname{vim}\left[\mathrm{Tf}_{2} \mathrm{~N}\right]-\operatorname{LiTf}_{2} \mathrm{~N}$ mixture and the aqueous solution was measured by using pendant drop tensiometry. For example, for $\mathrm{a} \mathrm{C}_{3} \operatorname{vim}\left[\mathrm{Tf}_{2} \mathrm{~N}\right]-\mathrm{LiTf}_{2} \mathrm{~N}$ (molar ratio $=1: 1 / 20$ ) droplet of $c a .200 \mu \mathrm{m}$, the osmotic pressure $\Phi$ is already $1650 \mathrm{~Pa}$, which far exceeds the Laplace pressure $(\Delta P \approx$ $20 \mathrm{~Pa}$ ). The huge difference will drive water transport from the external water phase into the IL oil phase, and the minimum aqueous droplet generated through OPS should be about $R_{\min }=$ $2400 \mathrm{~nm}$ when $\Phi=\Delta P_{\max }$. It should be noted that, although the $\operatorname{LiTf}_{2} \mathrm{~N}$ salt shows good solubility in water, we neglected the possibility of $\operatorname{LiTf}_{2} \mathrm{~N}$ salt diffusing from the oil droplets into the continuous aqueous phase because $\operatorname{LiTf}_{2} \mathrm{~N}$ has multiple interactions with $\mathrm{C}_{n} \operatorname{vim}\left[\mathrm{Tf}_{2} \mathrm{~N}\right]$.

The droplets of the $\mathrm{C}_{n} \operatorname{vim}\left[\mathrm{Tf}_{2} \mathrm{~N}\right]-\mathrm{LiTf}_{2} \mathrm{~N}$ oil solution prepared in the microchannel are initially homogeneous and transparent. After being injected into the continuous aqueous phase, it is found that the droplets would spontaneously develop a cloudy appearance, and gradually change from clear to dark under transmission microscopy observation, as shown in Fig. S3. $\uparrow$ These results clearly indicate that sufficient osmotic pressure drives the water permeation from the aqueous phase into the oil phase, leading to the liquid-liquid phase separation process inside the oil droplets. In the microchannel the phase separation evolution as well as the resultant emulsion structure is clearly observable. Importantly, we found that the remarkable solubility of $\operatorname{LiTf}_{2} \mathrm{~N}$ in $\mathrm{C}_{n} \operatorname{vim}\left[\mathrm{Tf}_{2} \mathrm{~N}\right]$ and the variation of the $\mathrm{C}_{n} \operatorname{vim}\left[\mathrm{Tf}_{2} \mathrm{~N}\right]$ structure could provide great opportunities and flexibility to modulate the speed and kinetic pathways of this osmotically driven phase separation process. The highly kinetically controlled features of OPS would make it possible to access various phase-separated meta-structures, as illustrated qualitatively in the ternary phase diagram of the water- $\mathrm{LiTf}_{2} \mathrm{~N}-$ $\mathrm{C}_{n} \operatorname{vim}\left[\mathrm{Tf}_{2} \mathrm{~N}\right]$ system (Fig. $\mathrm{S} 4 \dagger$ ). In this work, we choose polymerizable $\mathrm{C}_{n} \operatorname{vim}\left[\mathrm{Tf}_{2} \mathrm{~N}\right]$ because it can be polymerized by UV light to freeze the metastable state during the OPS process. The arrested metastable structure can be easily characterized and analysis by SEM.

\section{Effect of $\operatorname{LiTf}_{2} \mathrm{~N}$ concentration on the OPS process}

The water diffusion speed is dictated by the osmotic difference resulting from the dissolved $\operatorname{LiTf}_{2} \mathrm{~N}$ salt. The kinetics of the observed phase separation in oil could be facilely controlled by varying the initial salt concentration. As a representative example, Fig. 3 shows the phase separation behaviour of a series of $\mathrm{C}_{3} \operatorname{vim}\left[\mathrm{Tf}_{2} \mathrm{~N}\right]$ oils with different amounts of dissolved $\operatorname{LiTf}_{2} \mathrm{~N}$ salts. After prolonged exposure (ca. $60 \mathrm{~min}$ ) to the aqueous phase, no appreciable phase separation was detected in the pure $\mathrm{C}_{3} \operatorname{vim}\left[\mathrm{Tf}_{2} \mathrm{~N}\right]$ droplet without the addition of $\operatorname{LiTf}_{2} \mathrm{~N}$ (Fig. 3a). The boundary of the oil droplet turned dark with prolonged exposure (Fig. $3 \mathrm{a}_{1}-\mathrm{a}_{4}$ ); the reason for this phenomenon is probably the interfacial instability at the water-oil interface. Indeed, after the polymerization of the oil droplets under UV irradiation the resultant polymer particles were dense from the outside to inside (Fig. S5 $\dagger$ ), and no phase separation was observed. By contrast, when a small amount (1/40 molar) of $\operatorname{LiTf}_{2} \mathrm{~N}$ salt was dissolved in 1 molar $\mathrm{C}_{3} \operatorname{vim}\left[\mathrm{Tf}_{2} \mathrm{~N}\right]$, the phase separation was initiated in a slow fashion. In this case, to better observe the phase separation process, the hydrophobic Nile red 

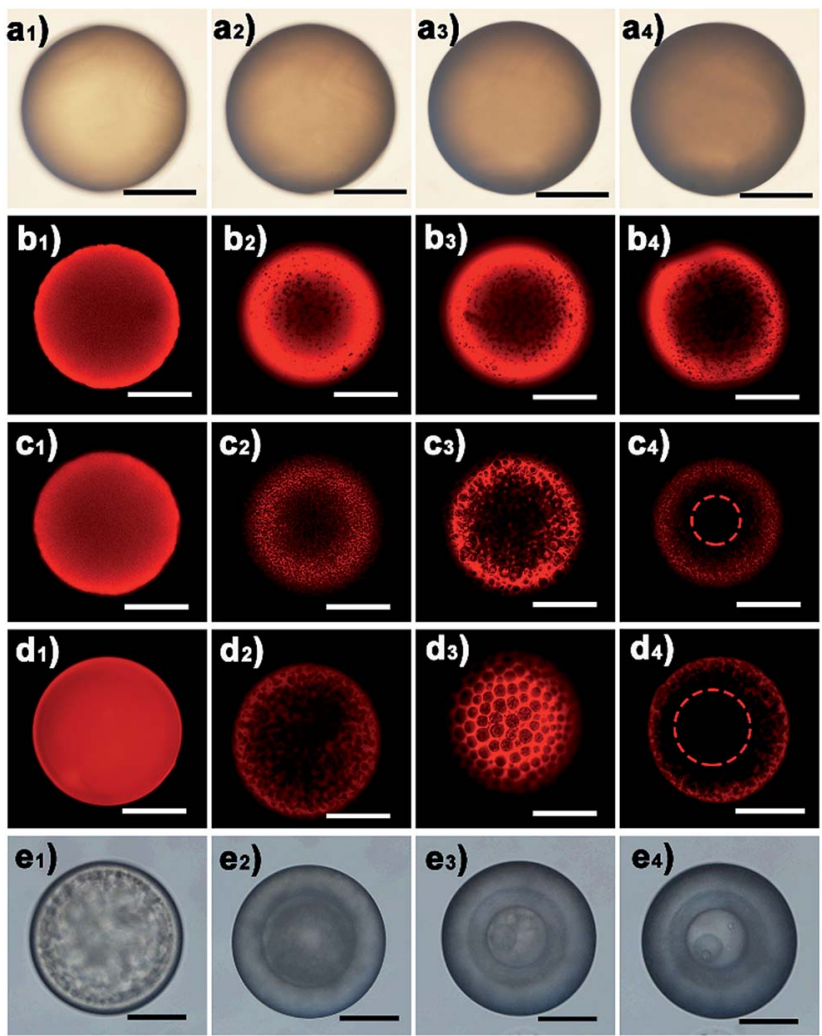

Fig. 3 Optical ( $a$ and e) and CLSM ( $b-d$ ) images of the emulsion structures induced by the osmotically driven water-oil phase separation process using the $\mathrm{C}_{3} \operatorname{vim}\left[\mathrm{Tf}_{2} \mathrm{~N}\right]-\mathrm{LiTf}_{2} \mathrm{~N}$ mixture with a molar ratio of $1: 0$ (a), $1: 1 / 40$ (b), $1: 1 / 10$ (c), $1: 1 / 5$ (d), and $1: 1 / 2$ (e) as the oil phase. The scale bar is $150 \mu \mathrm{m}$.

dye was added into the ionic liquid solution, which showed bright fluorescence in the oil phase and negligible fluorescence in the aqueous phase. As shown in Fig. 3b, the initial homogeneous phase (Fig. 3 $\mathrm{b}_{1}$ ) became heterogeneous, and water molecules were driven into the oil phase to form discrete smaller aqueous droplets after $1 \mathrm{~min}\left(\right.$ Fig. $3 b_{2}$ ). As the oil droplet moved downstream in the channel, more water molecules continuously diffused into the oil phase, finally resulting in a sea-island emulsion structure (Fig. $3 b_{3}$ and $b_{4}$ ). In this case, due to the lower osmotic driving force the OPS took place in an ultraslow fashion, and $10 \mathrm{~min}$ was required to achieve OPS at equilibrium. With the increasing amounts of $\operatorname{LiTf}_{2} \mathrm{~N}$ in $\mathrm{C}_{3}$ vim $\left[\mathrm{Tf}_{2} \mathrm{~N}\right]$, the enhanced driving force could expedite the OPS process. In the case of $1 / 10$ or $1 / 5$ molar $\operatorname{LiTf}_{2} \mathrm{~N}$ in 1 molar $\mathrm{C}_{3}$ vim $\left[\mathrm{Tf}_{2} \mathrm{~N}\right]$, the OPS occurred immediately and the transparent oil droplet became cloudy as it was injected into the continuous aqueous phase. In addition to the speed of OPS, the kinetic pathway also varied with the amount of $\operatorname{LiTf}_{2} \mathrm{~N}$. As can be seen from Fig. $3 \mathrm{c}$ and $d$, the structural evolution of the oil droplet went from homogeneous (Fig. $3 \mathrm{c}_{1}$ and $\mathrm{d}_{1}$ ), bicontinuous (Fig. $3 c_{2}$ and $d_{2}$ ), and multicompartmental (Fig. $3 c_{3}$ and $d_{3}$ ) to a double emulsion structure (Fig. $3 \mathrm{c}_{4}$ and $\mathrm{d}_{4}$ ). The bicontinuous structure was further confirmed in the SEM image in Fig. S20. $\dagger$ Compared with the $\mathrm{C}_{3} \operatorname{vim}\left[\mathrm{Tf}_{2} \mathrm{~N}\right]-\operatorname{LiTf}_{2} \mathrm{~N}$ solution at a molar ratio of $1: 1 / 5$, the resulting double emulsion structure obtained by the $1: 1 / 10 \quad \mathrm{C}_{3} \operatorname{vim}\left[\mathrm{Tf}_{2} \mathrm{~N}\right]-\operatorname{LiTf}_{2} \mathrm{~N}$ system shows a smaller inner core and a thicker porous shell (Fig. $3 \mathrm{c}_{4}$ and $\mathrm{d}_{4}$ ). When more $\operatorname{LiTf}_{2} \mathrm{~N}$ salt was dissolved in $\mathrm{C}_{3} \operatorname{vim}\left[\mathrm{Tf}_{2} \mathrm{~N}\right]$, the phase separation behaviour of the $\mathrm{C}_{3} \operatorname{vim}\left[\mathrm{Tf}_{2} \mathrm{~N}\right]-\operatorname{LiTf}_{2} \mathrm{~N}$ system changed dramatically. Fig. 3e shows the OPS evolution process of the $\mathrm{C}_{3} \operatorname{vim}\left[\mathrm{Tf}_{2} \mathrm{~N}\right]-\operatorname{LiTf}_{2} \mathrm{~N}$ at a molar ratio of $1: 1 / 2$. Quite different from the induced structures described above, in this case the onion-like emulsion structure was formed through OPS. Such a violent change of the structure induced through OPS can be attributed to the rapid diffusion of a large amount of water into the $\mathrm{C}_{3} \operatorname{vim}\left[\mathrm{Tf}_{2} \mathrm{~N}\right]-\mathrm{LiTf}_{2} \mathrm{~N}$ oil droplet (Fig. 3e $\mathrm{e}_{1}$ ). Spinodal decomposition was first induced, leading to a double emulsion structure with a $\mathrm{C}_{3} \operatorname{vim}\left[\mathrm{Tf}_{2} \mathrm{~N}\right]$ rich shell and a water rich core (Fig. $3 \mathrm{e}_{2}$ ). Inside the droplet the liquid-liquid phase separation then proceeds continuously through self-similar cycles (Fig. S4d†) of mass transfer, spinodal decomposition, and coalescence into a multiple layer structure (Fig. $3 \mathrm{e}_{3}$ and $\left.e_{4}\right){ }^{34}$ The self-similar phase separation behaviour was quantitatively proved by the linear relationship of each shell diameter, as shown in Fig. S6. $\uparrow$ It should be pointed out that the abovementioned phase separation behaviour is highly reproducible. As can be seen in Fig. $57, \dagger$ large scale fabrication of the same phase separation droplets was achieved by using the microfluidic method. Clearly, these results demonstrate that the speed and kinetic pathways of OPS as well as the induced structure could be facilely modulated by simply varying $\operatorname{LiTf}_{2} \mathrm{~N}$ in the $\mathrm{C}_{3} \operatorname{vim}\left[\mathrm{Tf}_{2} \mathrm{~N}\right]-\mathrm{LiTf}_{2} \mathrm{~N}$ system.

\section{Effect of the alkyl chain on the OPS process}

Besides the thermodynamic driving force, varying the alkyl length of the $\mathrm{C}_{n} \operatorname{vim}\left[\mathrm{Tf}_{2} \mathrm{~N}\right]$ could adjust the hydrophobicity of ionic liquids, and thus provides another means to modulate the kinetics of the OPS through a change of the kinetic barrier. In the $\mathrm{C}_{n} \operatorname{vim}\left[\mathrm{Tf}_{2} \mathrm{~N}\right]-\mathrm{LiTf}_{2} \mathrm{~N}$ system, increasing the hydrophobicity of ILs could decrease the speed of the osmotically driven water transport, leading to the change of kinetic pathways of the phase separation process (the hydrophobicity increased with the increase of the alkyl chain length, which is demonstrated by the solubility test in Fig. S18 $\dagger$ ). In the case of $\mathrm{C}_{3} \operatorname{vim}\left[\mathrm{Tf}_{2} \mathrm{~N}\right]-$ $\operatorname{LiTf}_{2} \mathrm{~N}$ (molar ratio: $1: 1 / 5$ ), the ionic liquid shows a relative high affinity toward water molecules. The liquid-liquid OPS process occurred fast accompanied with the structural evolution from bicontinuous and multicompartmental to the double emulsion structure. When the $\mathrm{C}_{6} \operatorname{vim}\left[\mathrm{Tf}_{2} \mathrm{~N}\right]-\mathrm{LiTf}_{2} \mathrm{~N}$ system with the same concentration of $\operatorname{LiTf}_{2} \mathrm{~N}$ salt was used, the structural evolution during OPS also went from bicontinuous and coalescence to sea-island, and Ostwald ripening to the double emulsion structure. However, the higher hydrophobicity of hexyl $(n=6)$ than of propyl $(n=3)$ gave rise to a clear reduction of the speed of the OPS process and the double emulsion structure with a smaller aqueous core and a thicker porous shell (Fig. 4a, b and e, f). Further increasing the alkyl length of ionic liquids would significantly enhance the kinetic barrier of water transport. As a result, the speed of the OPS process became remarkably slower. On the other hand, due to the change of the 

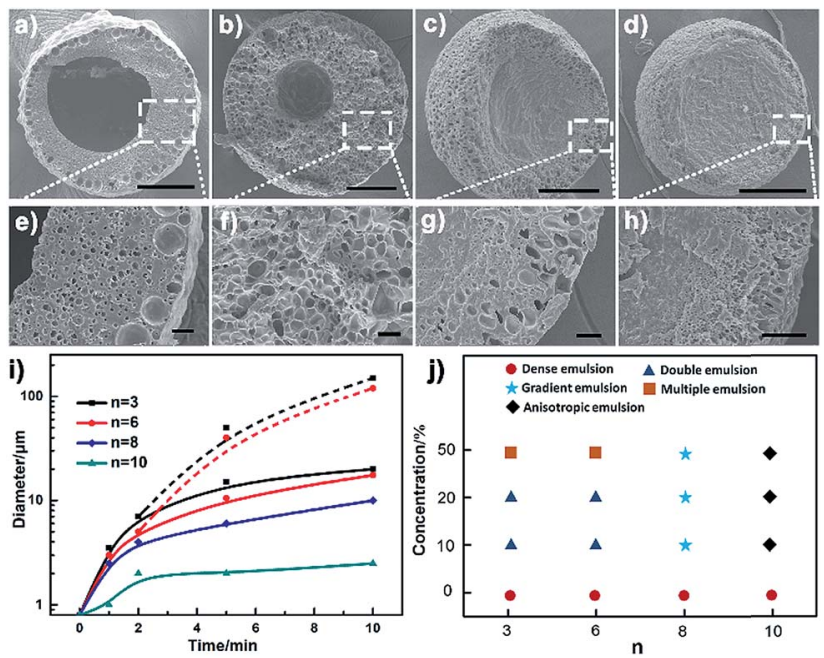

Fig. 4 SEM images of polymerized emulsions after 10 minutes of phase separation by using the $\mathrm{C}_{n} \operatorname{vim}\left[\mathrm{Tf}_{2} \mathrm{~N}\right]-\mathrm{LiTf}_{2} \mathrm{~N}(1: 1 / 5)$ mixture, $n=$ 3 (a and e), $n=6$ (b and f), $n=8$ ( $\mathrm{c}$ and g) and $n=10$ ( $\mathrm{d}$ and h). (i) Average pore diameter during the phase separation process by using the $\mathrm{C}_{n} \operatorname{vim}\left[\mathrm{Tf}_{2} \mathrm{~N}\right]-\mathrm{LiTf}_{2} \mathrm{~N}(1: 1 / 5)$ mixture (solid line: shell pore diameter, dashed line: core diameter) and (j) morphology diagram of polymerized complex emulsions induced by using ILs containing different $\mathrm{LiTf}_{2} \mathrm{~N}$ amounts. Scale bars are $150 \mu \mathrm{m}(\mathrm{a}-\mathrm{d})$ and $20 \mu \mathrm{m}(\mathrm{e}-\mathrm{h})$.

kinetic pathway, the structural evolution induced by OPS and the resultant equilibrium structure are quite different. For the more hydrophobic $\mathrm{C}_{8} \operatorname{vim}\left[\mathrm{Tf}_{2} \mathrm{~N}\right]-\mathrm{LiTf}_{2} \mathrm{~N}$ system no double emulsion structure could be formed during the OPS process, and instead only an anisotropic porous sphere with an isolated porous core and interconnected micrometer-sized porous shell was induced (Fig. 4c and g). When we further increase the alkyl chain length from octyl to decanyl, the OPS of $\mathrm{C}_{10} \operatorname{vim}\left[\mathrm{Tf}_{2} \mathrm{~N}\right]-\operatorname{LiTf}_{2} \mathrm{~N}$ under comparable conditions afforded the sphere with a dense core and thin porous shell, namely the "ring porous sphere", at equilibrium (Fig. $4 \mathrm{~d}$ and h). Fig. $4 \mathrm{i}$ summarizes the effect of the alkyl length of the ionic liquid on the structural evolution of the $\mathrm{C}_{n} \operatorname{vim}\left[\mathrm{Tf}_{2} \mathrm{~N}\right]-\operatorname{LiTf}_{2} \mathrm{~N}$ system at the same molar ratio of 1 to $1 / 5$. Fig. $4 \mathrm{j}$ shows the diagram of the structure induced by the OPS using ionic liquids with different alkyl chains under different driving forces $\left(\operatorname{LiTf}_{2} \mathrm{~N}\right.$ concentrations). It should be noted that with the increase of the alkyl chain length, the interfacial tension between $\mathrm{C}_{n} \operatorname{vim}\left[\mathrm{Tf}_{2} \mathrm{~N}\right]$ and the $10 \%$ PVA aqueous solution was almost unchanged (Fig. S21 $\dagger$ ), which means it had no influence on the OPS process. In addition, when we used $\mathrm{C}_{8} \operatorname{vim}\left[\mathrm{Tf}_{2} \mathrm{~N}\right]$ or $\mathrm{C}_{10} \operatorname{vim}\left[\mathrm{Tf}_{2} \mathrm{~N}\right]$, increasing the salt concentration doesn't have a significant influence on the type of prepared emulsion. This is because with long alkyl chain lengths, the hydrophobicity of the ionic liquid generates a 'kinetic barrier', which could offset the driving force of osmotic pressure (Fig. S19†). These results clearly indicate that the variation of the alkyl length of ionic liquids could finely tune the kinetics of the OPS process and provide an efficient way to access diverse emulsion structures using a single-step procedure. To clearly prove that the OPS process is not a simple dissolution process, we prepared a double emulsion in which the $\mathrm{C}_{n} \operatorname{vim}\left[\mathrm{Tf}_{2} \mathrm{~N}\right]-\operatorname{LiTf}_{2} \mathrm{~N}$ oil and water were separated by another immiscible oil (PDMS). In this case, the simple dissolution process would not take place because $\mathrm{C}_{n} \operatorname{vim}\left[\mathrm{Tf}_{2} \mathrm{~N}\right]-\mathrm{LiTf}_{2} \mathrm{~N}$ oil and water were not in contact with each other. However, the water transport and phase separation still occurred. This is a solid demonstration that the OPS process is not a simple dissolution process.

Based on the above results, it is conceivable that adjusting the IL molecular structure together with varying the thermodynamic driving force (namely the $\operatorname{LiTf}_{2} \mathrm{~N}$ concentration) would provide unprecedented freedom and flexibility in controlling or modulating the kinetics of OPS of the $\mathrm{C}_{n} \operatorname{vim}\left[\mathrm{Tf}_{2} \mathrm{~N}\right]-\mathrm{LiTf}_{2} \mathrm{~N}$ system, and diverse thermodynamically metastable structures could be created and arrested using one system. As a demonstration, Fig. 5 shows several typical structures induced by adjusting the $\operatorname{LiTf}_{2} \mathrm{~N}$ concentration and molecular structure, including the sea-island emulsion structure (Fig. $5 \mathrm{a}_{1}$ and $\mathrm{a}_{2}$ ), bicontinuous emulsion structure (Fig. $5 b_{1}$ and $b_{2}$ ), multicompartmental structure with different sizes (Fig. $5 c_{1}, c_{2}$ and $d_{1}$, $\mathrm{d}_{2}$ ), dense core with thin porous shell structure (Fig. $5 \mathrm{e}_{1}$ and $\mathrm{e}_{2}$ ), gradient emulsion structure (Fig. $5 \mathrm{f}_{1}$ and $\mathrm{f}_{2}$ ), double emulsion structure (Fig. $5 g_{1}$ and $g_{2}$ ), and complex triple and multiple emulsion structure (Fig. $5 h_{1}$ and $h_{2}$ ). Besides the fact that the internal structure of the oil droplet could also be adjusted in a wide range, the shell thickness, the pore diameter and the pore distribution are also finely tunable (Fig. S8-S10†). It should be noted that a gradient emulsion (Fig. $5 f_{1}$ and $f_{2}$ ) could be prepared with the $5: 1 \mathrm{C}_{8} \operatorname{vim}\left[\mathrm{Tf}_{2} \mathrm{~N}\right]-\mathrm{LiTf}_{2} \mathrm{~N}$ mixture. During the OPS process, water was absorbed into the oil phase. Subsequent water migration from the outer to the inner region of the oil phase was quite slow because of the hydrophobicity of $\mathrm{C}_{8}$ vim $\left[\mathrm{Tf}_{2} \mathrm{~N}\right]$. Consequently, the outer region of the oil phase contained more water than the inner region, which generated a water gradient from the outside to the inside.

\section{Effect of salt concentration in the aqueous phase on the OPS process}

For a given $\mathrm{C}_{n} \operatorname{vim}\left[\mathrm{Tf}_{2} \mathrm{~N}\right]-\operatorname{LiTf}_{2} \mathrm{~N}$ system the addition of salt in the aqueous phase could adjust the gradient of osmotic pressure between the oil phase and the aqueous phase, thus providing an alternative way of tailoring the thermodynamic driving force to further impact the kinetics involved in the OPS process. The transport of water molecules into or out of the IL oil phase during the phase separation process could be slowed down or stopped at any stage by simply adjusting the salt concentration in the aqueous phase. In our work, to demonstrate the ability to precisely control the kinetics through the alteration of the salt concentration in the aqueous phase, a series of parallel experiments was performed by exposing one oil droplet with a given $\mathrm{C}_{3} \operatorname{vim}\left[\mathrm{Tf}_{2} \mathrm{~N}\right]-\operatorname{LiTf}_{2} \mathrm{~N}$ composition to different concentrations of a $\mathrm{NaCl}$ aqueous phase $\left(0.375 \mathrm{~mol} \mathrm{~L}^{-1}\right.$ to $\left.3.5 \mathrm{~mol} \mathrm{~L}^{-1}\right)$, respectively. Fig. 6 presents the optical images of the pendent oil drops after their exposure to a $\mathrm{NaCl}$ aqueous solution for $10 \mathrm{~min}$. Due to the insufficient osmotic pressure of pure $\mathrm{C}_{3} \operatorname{vim}\left[\mathrm{Tf}_{2} \mathrm{~N}\right]$, the OPS didn't take place as described above. As expected, the presence of the salt in the aqueous phase would further weaken the driving force for OPS, 

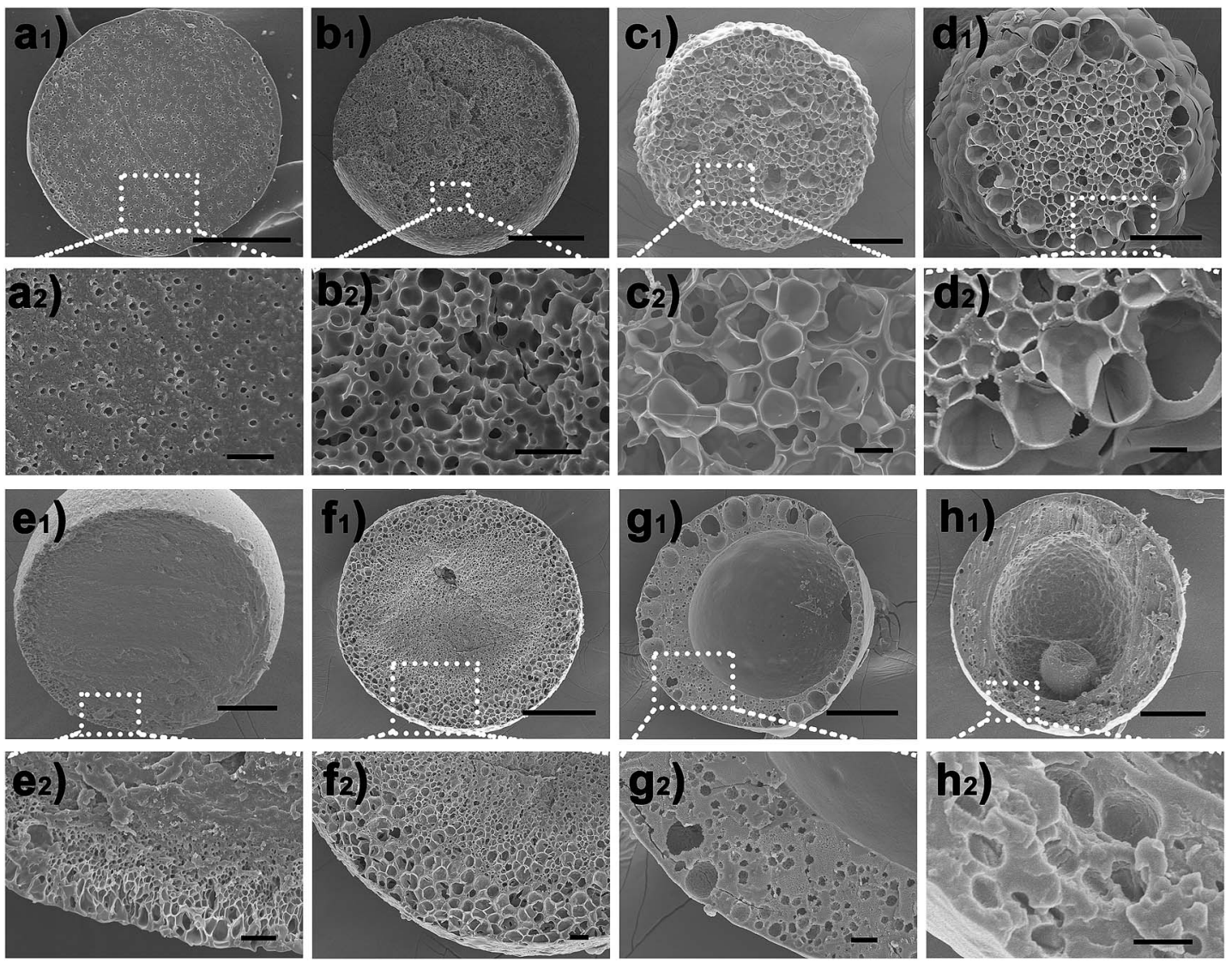

Fig. 5 (a-h) SEM images of diverse emulsion structures induced by judicious choosing of phase separation conditions. (a) Sea-island structure, (b) bicontinuous structure, (c and d) multicompartment structure, (e) anisotropic structure, (f) gradient structure, (g) double emulsion structure, and $(h)$ multiple emulsion structure. Scale bars are $100 \mu \mathrm{m}\left(a_{1}-h_{1}\right)$ and $10 \mu m\left(a_{2}-h_{2}\right)$.

and the pendent droplets of pure $\mathrm{C}_{3} \operatorname{vim}\left[\mathrm{Tf}_{2} \mathrm{~N}\right]$ in all the cases remained transparent in appearance without the occurrence of the permeation of water molecules into the IL oil phase (Fig. $6 \mathrm{a}_{1}-\mathrm{a}_{6}$ ). However, in the case of $\mathrm{C}_{3} \operatorname{vim}\left[\mathrm{Tf}_{2} \mathrm{~N}\right]$ containing a small amount of $\operatorname{LiTf}_{2} \mathrm{~N}\left(\mathrm{C}_{3} \operatorname{vim}\left[\mathrm{Tf}_{2} \mathrm{~N}\right]: \operatorname{LiTf}_{2} \mathrm{~N}=1: 1 / 50\right)$, even in the presence of $0.375 \mathrm{~mol} \mathrm{~L}^{-1} \mathrm{NaCl}$ the osmotic pressure difference between the IL oil and aqueous phase was still large enough to induce the OPS process quickly, and after $10 \mathrm{~min}$ the droplet became cloudy and dark as shown in the optical image (Fig. $6 \mathrm{~b}_{1}$ ). But, with the increasing amount of the $\mathrm{NaCl}$ aqueous phase, the oil droplets only became gray and semi-transparent at a comparable time, indicating that the OPS process was appreciably slowed down (Fig. 6b). When a sufficient amount of $\mathrm{NaCl}$ was added $\left(\geq 2.250 \mathrm{~mol} \mathrm{~L}^{-1} \mathrm{NaCl}\right.$ solution), the OPS process could be completely inhibited or blocked, and the droplets of $\mathrm{C}_{3} \operatorname{vim}\left[\mathrm{Tf}_{2} \mathrm{~N}\right]-\mathrm{LiTf}_{2} \mathrm{~N}$ remain transparent. As more LiTf $_{2} \mathrm{~N}$ salt was dissolved in $\mathrm{C}_{3} \operatorname{vim}\left[\mathrm{Tf}_{2} \mathrm{~N}\right]$, the enhanced osmotic pressure accelerated the transport of water molecules into the oil phase, and thus sped up the OPS process (see section A in Fig. 6). Nevertheless, for all $\mathrm{C}_{3} \operatorname{vim}\left[\mathrm{Tf}_{2} \mathrm{~N}\right]-\mathrm{LiTf}_{2} \mathrm{~N}$ cases it was found that the rigorous adjustment of the salt concentration in the aqueous phase could precisely regulate the speed of the OPS process (see section B in Fig. 6), stop it at any stage and even inhibit the OPS process (see section C in Fig. 6).

\section{Reconfigurable OPS process}

In this work, we also found that the direction of the mentioned OPS process could be effectively controlled by altering the salt $(\mathrm{NaCl})$ concentration in the outer aqueous phase. Fig. $7 \mathrm{a}-\mathrm{d}$ show the representative optical evolution of $\mathrm{C}_{8} \operatorname{vim}\left[\mathrm{Tf}_{2} \mathrm{~N}\right]-\mathrm{LiTf}_{2} \mathrm{~N}$ (molar ratio: $1: 1 / 10$ ) oil droplets exposed to a pure water phase. As described above, the osmotic pressure gradient between the IL oil phase and the aqueous phase drives the transport of water into oil to induce the OPS. With the permeation of water molecules the appearance of oil droplets changes gradually from initially transparent to cloudy semi-transparent, and finally to a dark emulsion state at equilibrium after several minutes. Interestingly, when a concentrated $\mathrm{NaCl}$ solution was subsequently added in the equilibrium system, the dehydration of the emulsion droplets was initiated and the water molecules absorbed inside the oil droplets could be retracted back into the aqueous phase and correspondingly the appearance of emulation droplets evolved from dark to transparent (Fig. 7e-h). Surprisingly, we found that the heterogeneous emulsion structure induced by OPS could be restored into the initial homogeneous oil phase. To better distinguish the structural evolution of oil droplets, a dye-doped $\mathrm{C}_{6} \operatorname{vim}\left[\mathrm{Tf}_{2} \mathrm{~N}\right]-\mathrm{LiTf}_{2} \mathrm{~N}$ (molar ratio: $1: 1 / 5$ ) oil system was employed for the OPS and its reverse process (dehydration). Clearly, similar results were observed (Fig. 7i-o). The 


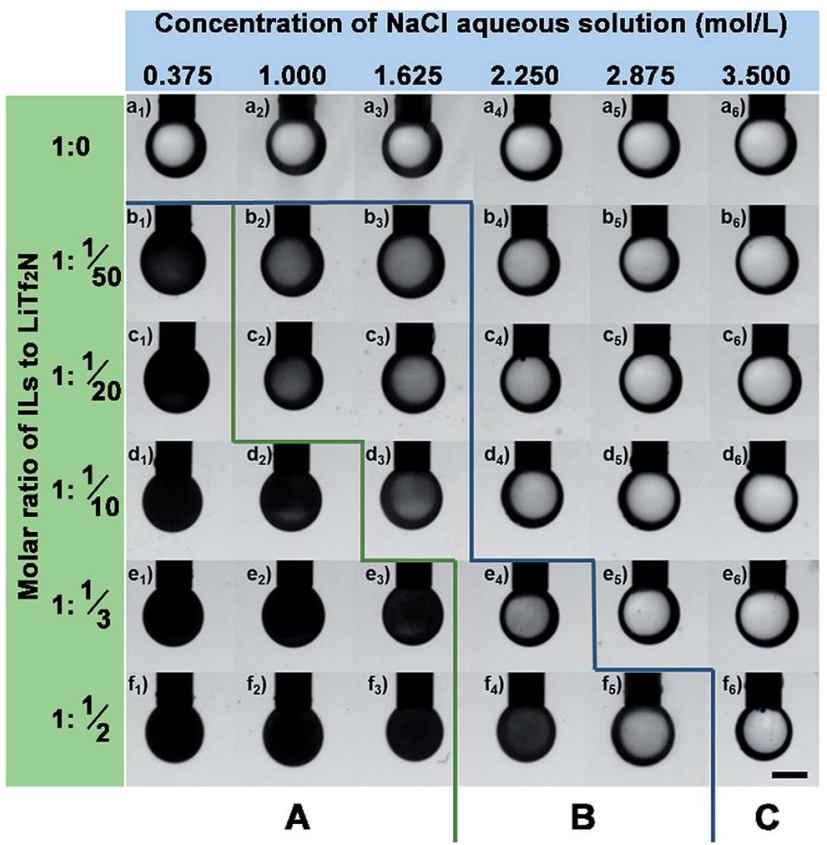

Fig. 6 Optical images of the $\mathrm{C}_{3} \operatorname{vim}\left[\mathrm{Tf}_{2} \mathrm{~N}\right]-\mathrm{LiTf}_{2} \mathrm{~N}$ droplets after exposure to the $\mathrm{NaCl}$ aqueous solution for 10 minutes of phase separation. Molar ratio of $\mathrm{C}_{3} \operatorname{vim}\left[\mathrm{Tf}_{2} \mathrm{~N}\right]-\mathrm{LiTf}_{2} \mathrm{~N}$ is increased from $1: 0$ to $1: 1 / 2$. The concentration of the $\mathrm{NaCl}$ aqueous solution is increased from 0.375 to $3.5 \mathrm{~mol} \mathrm{~L}^{-1}$. The scale bar is $300 \mu \mathrm{m}$.

heterogeneous structure induced by OPS could be returned to the initial homogeneous oil phase by changing the direction of the osmotic pressure imbalance. During the reverse process of phase separation (dehydration), an obvious boundary between the phase separation region and the non-phase separation region was clearly observed. Finally, the complex emulsion reverted to a homogeneous droplet. Indeed, DLS measurement confirmed that the restored phase is homogeneous (Fig. S11 $\dagger$ ), and no porous structure was detected after the polymerization of the restored oil droplets (see inset in Fig. 7h). This result implies that the process of the OPS in the $\mathrm{C}_{n} \operatorname{vim}\left[\mathrm{Tf}_{2} \mathrm{~N}\right]-\mathrm{LiTf}_{2} \mathrm{~N}$ oil system could be modulated on demand by the aid of osmotic pressure imbalance. Over the past few decades, the osmotic pressure gradient has been widely exploited to control the direction of water transport across the oil layer between both aqueous phases in multiple emulsion systems. To the best of our knowledge, however, the described phenomenon that the heterogeneous multiple phase formed through phase separation was again restored to the initial homogeneous oil phase by changing the direction of the osmotic pressure imbalance has never been reported so far. This important finding together with the widely adjustable thermodynamic driving force and kinetic barrier indicates that the $\mathrm{C}_{n} \operatorname{vim}\left[\mathrm{Tf}_{2} \mathrm{~N}\right]-$ $\operatorname{LiTf}_{2} \mathrm{~N}$ mixture is a novel oil system, with which a highly kinetically controlled and reconfigurable OPS process could be realized.

\section{Remarkable extendibility of the OPS using the $\mathrm{C}_{n} \operatorname{vim}\left[\mathrm{Tf}_{2} \mathrm{~N}\right]-$ LiTf $_{2} \mathbf{N}$ system}

Due to the extraordinary multiple intermolecular interactions, including weak nonspecific forces (van der Waals, solvophobic, and dispersion forces) and strong specific forces (hydrogen bonding, dipole-dipole, and electron pair donor/ acceptor interactions), ionic liquids exhibit a peculiar ability to dissolve or disperse a broad range of substances or nanoobjects. ${ }^{35,36}$ This unique feature implies that the $\mathrm{C}_{n} \operatorname{vim}\left[\mathrm{Tf}_{2} \mathrm{~N}\right]-$ $\operatorname{LiTf}_{2} \mathrm{~N}$ system described here should serve as a general phase separation platform, and the phase separation process of numerous materials could be facilely achieved through dissolution or dispersion of the relevant materials in the $\mathrm{C}_{n} \operatorname{vim}\left[\mathrm{Tf}_{2} \mathrm{~N}\right]-\mathrm{LiTf}_{2} \mathrm{~N}$ system. This strategy together with online photo-polymerization would afford various porestructured functional materials, especially those that are inaccessible using conventional methods. As proof of our concept, several types of substances and nano-objects were dissolved or dispersed in $\mathrm{C}_{n} \operatorname{vim}\left[\mathrm{Tf}_{2} \mathrm{~N}\right]-\operatorname{LiTf}_{2} \mathrm{~N}$, and the OPS behavior of the $\mathrm{C}_{n} \operatorname{vim}\left[\mathrm{Tf}_{2} \mathrm{~N}\right]-\mathrm{LiTf}_{2} \mathrm{~N}$ system remained even after the addition of other substances or nano-objects, and various emulsion mixtures were obtained. Indeed, it is found that the OPS structures were formed. In our case, eight classes of functional species, including ethoxylated trimethylolpropane triacrylate (cross-linker), an azobenzene-type monomer (photo-responsive compound), a tetraphenylethylene luminogen, $N$-acryloxysuccinimide (bioorthogonal reactive compound), graphene, carbon tubes, gold and $\mathrm{TiO}_{2}$ nanoparticles were incorporated into the $\mathrm{C}_{n} \operatorname{vim}\left[\mathrm{Tf}_{2} \mathrm{~N}\right]-\mathrm{LiTf}_{2} \mathrm{~N}$ system, respectively (the chemical structures of the used molecules are shown in Fig. S12 $\dagger$ ). Fig. 8 shows the optical and SEM images after OPS followed by photopolymerization. Clearly, diverse functional porous materials were conveniently fabricated through the OPS strategy. And the successful incorporation of the functional species into the resulting porous materials was verified using different analytical methods, as shown in Fig. S13-S16. $\dagger$ In particular, for pristine carbon and other inorganic nanomaterials, which are difficult or impossible to be processed using conventional methods, our strategy offers an efficient way to produce porestructured materials while still maintaining their intrinsic properties. Additionally, after the OPS process and polymerization, a series of functional porous materials could also be derived from the counter anion exchange of the original porous poly(ionic liquid)s (the Experimental method is in the ESI $\dagger$ ). In this way, porous materials with oxidative $\left(\mathrm{AuCl}_{4}{ }^{-}\right)$, reductive (vitamin $\mathrm{C}$ ), and bio-active (dopamine) functions were created, as shown in Fig. S17. $\dagger$

Apart from the spherical porous material, the OPS of the $\mathrm{C}_{n} \operatorname{vim}\left[\mathrm{Tf}_{2} \mathrm{~N}\right]-\mathrm{LiTf}_{2} \mathrm{~N}$ system could be extended for large-scale fabrication of porous films or membranes, which have wide applications in separation, catalysis, electronics and so on. As a demonstration, $\mathrm{C}_{8} \operatorname{vim}\left[\mathrm{Tf}_{2} \mathrm{~N}\right]-\operatorname{LiTf}_{2} \mathrm{~N}(1: 1 / 10)$ was employed for producing functional porous films. The $\mathrm{C}_{8} \operatorname{vim}\left[\mathrm{Tf}_{2} \mathrm{~N}\right]-$ $\operatorname{LiTf}_{2} \mathrm{~N}$ oil film was first deposited on a glass slide by the spincoating method. After immersion of the coated substrate in the water phase for OPS the resultant porous film was solidified by photopolymerization. This simple three-step procedure afforded large-area poly(IL) films with a well-defined interconnected pore structure, as shown in Fig. 9a. Poly(IL)s bearing $\mathrm{Tf}_{2} \mathrm{~N}^{-}$are believed to have good ion transport 

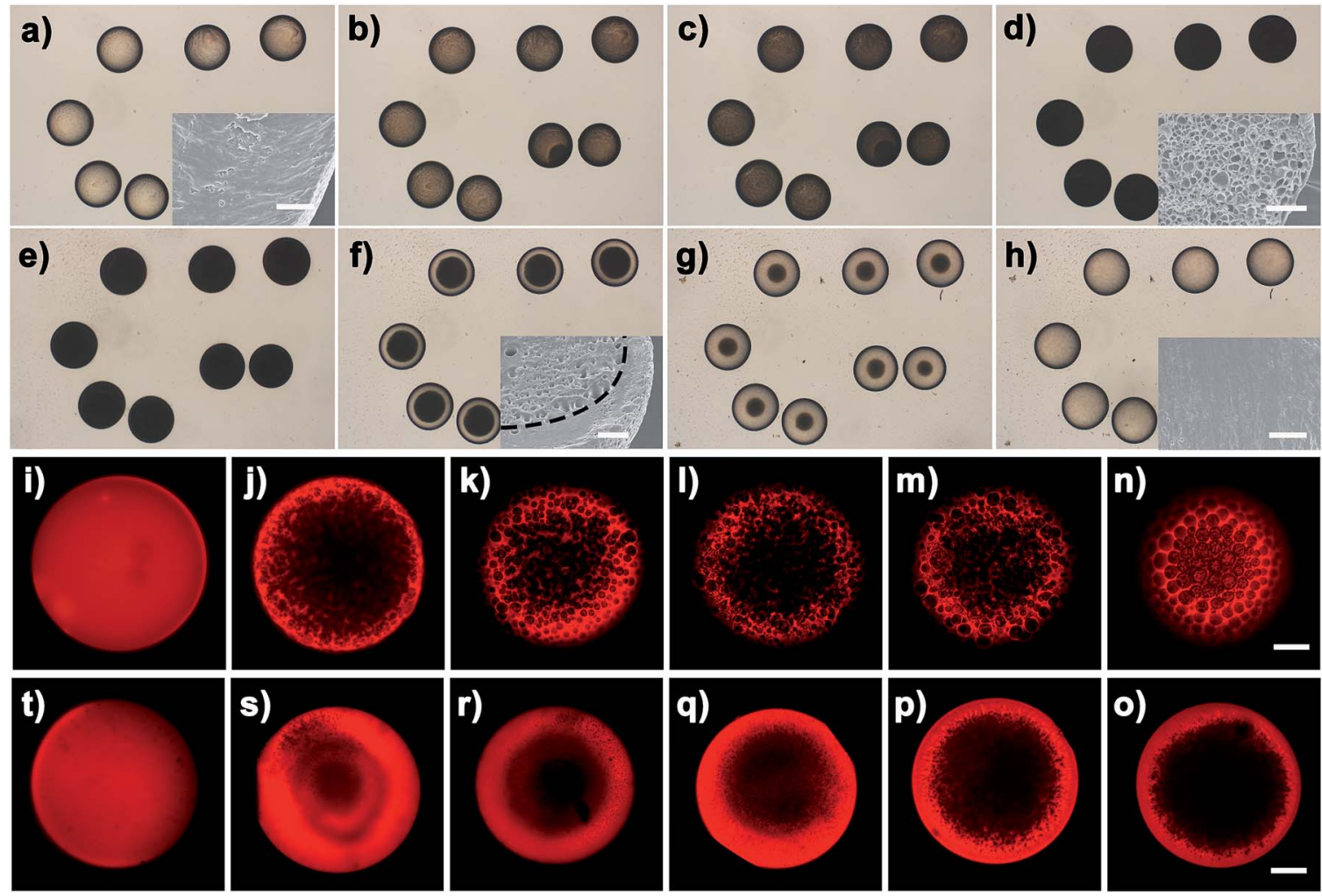

Fig. 7 (a-d) Optical images of the water absorption induced phase separation process by using $\mathrm{C}_{8}$ Vim- $\mathrm{Tf}_{2} \mathrm{~N} / \mathrm{LiTf}_{2} \mathrm{~N}(1: 1 / 10)$ microdroplets dispersed in water; $(\mathrm{e}-\mathrm{h})$ optical images of the reverted phase separation process from the phase-separated heterogeneous state to the homogeneous oil phase by redrawing the water molecules taken up after adding $\mathrm{NaCl}$ in the surrounding aqueous solution; the insets are SEM images of the complex emulsions. (i-t) CLSM monitoring of the reconfigurable OPS process by using $\mathrm{C}_{6} \mathrm{vim}\left[\mathrm{Tf}_{2} \mathrm{~N}\right]-\mathrm{LiTf}_{2} \mathrm{~N}(1: 1 / 5)$ microdroplets doped with dye molecules. Scale bars are $400 \mu \mathrm{m}$ (a-h), $15 \mu \mathrm{m}$ (insets) and $100 \mu \mathrm{m}$ (i-t).

efficiency. ${ }^{37}$ As can be seen in Fig. 9c, the prepared poly(IL) film interacting with $\operatorname{LiTf}_{2} \mathrm{~N}$ salt shows ion transport properties, and these properties increased dramatically when the film composite was treated with aqueous vapor. In our work, the capillary force of the prepared porous film was exploited to introduce a 3,4-ethoxylenedioxythiophene (EDOT) monomer into the interconnected pore channels, and the subsequent polymerization using chloroauric acid as the oxidative agent led to an ion-conductive PIL film with integrated electric conductivity. The SEM image in Fig. 9b shows the structure of a composite film. The prepared composite film possesses a bi-channel structure for both ion and electron transport. As shown in Fig. 9d, in a drying state, the composite film shows electron conductivity of the PEDOT channel after being treated with $\mathrm{I}_{2}$ vapour. When the film was treated with water vapour, enhanced conductivity was detected, which is attributed to the additional ion conductivity of the PIL- $\operatorname{LiTf}_{2} \mathrm{~N}$ channel. In principle, all recipes demonstrated above regarding droplets could also be used to construct functional porous materials in the film format. All these results indicate that the application scope of the OPS using the $\mathrm{C}_{n} \operatorname{vim}\left[\mathrm{Tf}_{2} \mathrm{~N}\right]-\mathrm{LiTf}_{2} \mathrm{~N}$ system could be greatly extended, presenting tremendous potential for facilely developing functional porous materials through a simple OPS process.

\section{Discussion}

Over the past few decades, exploiting mass transfer to induce water/oil phase separation for the creation of multiple emulsions has been intensively investigated. Most commonly, homogeneous ternary mixtures composed of two immiscible liquids and a cosolvent, miscible with both liquids (e.g., a short chain alcohol, THF, or acetonitrile), have been employed in most studies..$^{34,38-41}$ Once the mixture systems are brought into contact with the aqueous phase, the rapid diffusion of cosolvent into the aqueous phase can induce local supersaturation near the interface, thus giving rise to water/oil liquid phase separation and spontaneous formation of an emulsion structure. Such spontaneous liquid-liquid phase separation, referred to as selfemulsification or spontaneous emulsification, ${ }^{41}$ has also been observed in many oil systems with oil-soluble surfactants or amphiphilic block copolymers. But in these cases the phase separation process is relatively slow, and only simple emulsion structures like multicore morphologies are generally induced. The mechanism of this phenomenon is still not completely understood, and interfacial turbulence, negative interfacial tension, and diffusion and stranding were prominently proposed for the explanation of these spontaneous processes. ${ }^{42}$ Recently, T. P. Russell and R. C. Hayward have reported that the presence of salt impurity aggregates within the chloroform 

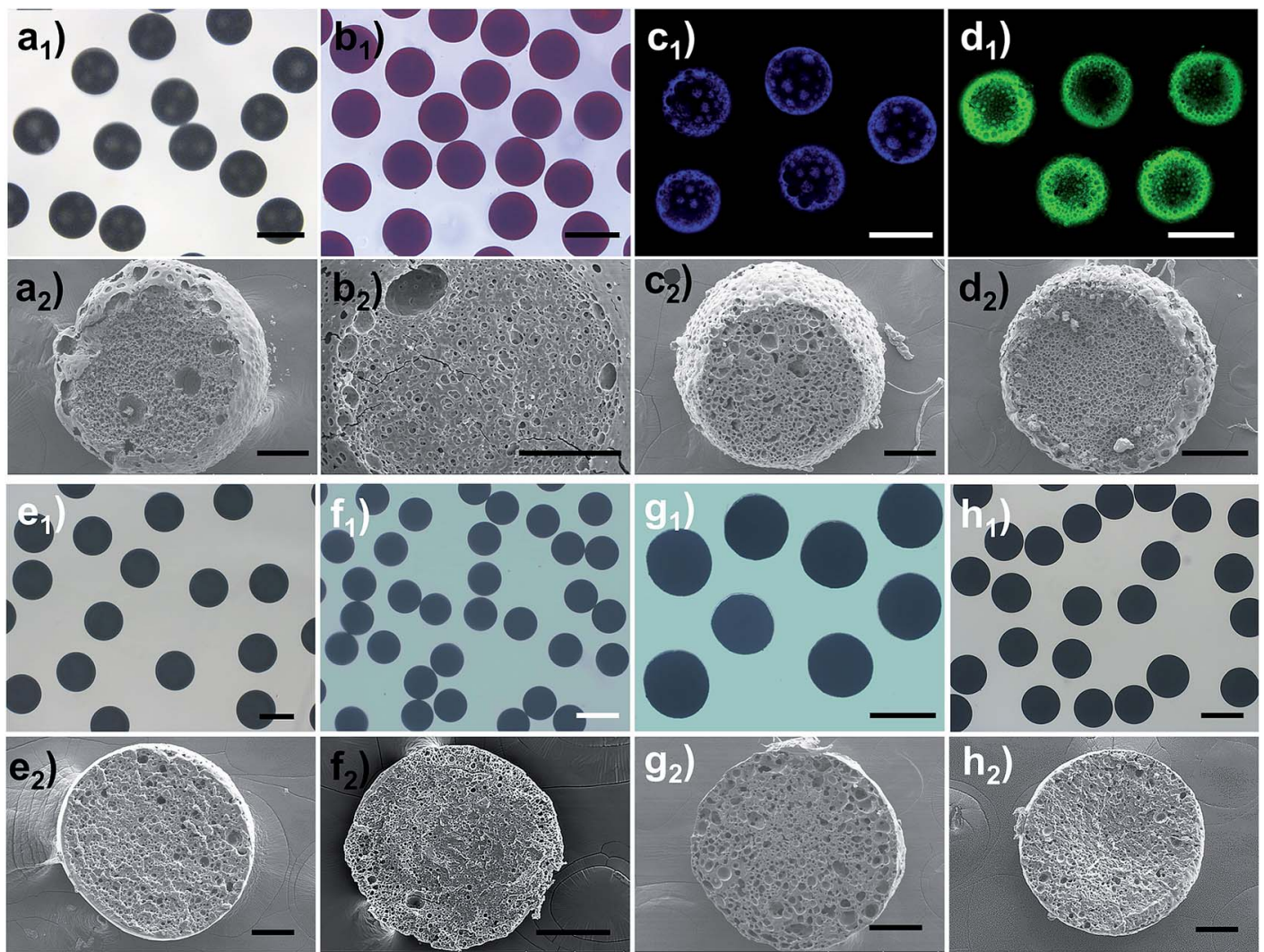

Fig. 8 Great extensibility of our proposed osmotically driven phase separation. Optical and SEM images of the formed pore-structured spheres by using $\mathrm{C}_{3} \operatorname{vim}\left[\mathrm{Tf}_{2} \mathrm{~N}\right]-\mathrm{LiTf}_{2} \mathrm{~N}$ as a general phase separation carrier platform for realizing the phase separation of various substances: (a $\left.{ }_{1-2}\right)$ ETPTA, $\left(b_{1-2}\right)$ azobenzene-type monomer, $\left(c_{1-2}\right)$ AlE-type monomer, $\left(d_{1-2}\right)$ bioorthogonal monomer (click reaction with GOX-FITC enzyme), $\left(e_{1-2}\right)$ TiO 2 particles, $\left(f_{1-2}\right)$ Au nanoparticles, $\left(g_{1-2}\right)$ carbon nanotubes, and $\left(h_{1-2}\right)$ graphene. Scale bars are $400 \mu m\left(a_{1}-h_{1}\right)$ and $100 \mu m\left(a_{2}-h_{2}\right)$.
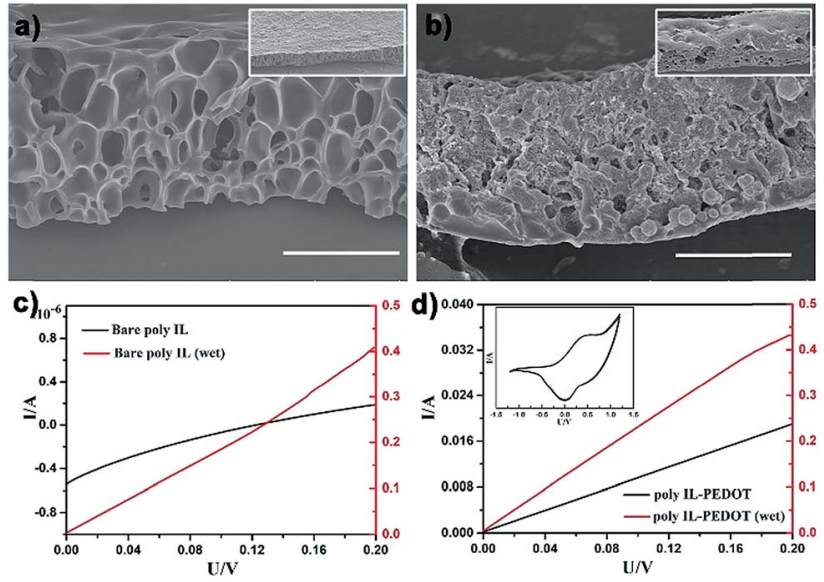

Fig. 9 SEM images of a bicontinuous poly(ionic liquid) membrane (a) and poly(ionic liquid)-PEDOT composite (b). Electrochemical curves of bare bicontinuous poly(ionic liquid) in the dry and wet state (c). Electrochemical curves for poly(ionic liquid)-PEDOT (doping with $\mathrm{I}_{2}$ vapour) in the dry and wet state (d); the inset image is the CV sweep of the poly(ionic liquid)-PEDOT membrane. The scale bar is $20 \mu \mathrm{m}$.

solutions of amphiphilic block copolymers could provide an osmotic driving force, triggering a spontaneous emulsification process after the organic phase was brought into contact with water. ${ }^{43}$ Under the osmotic driving force water molecules were drawn out of the surrounding water phase through chloroform, each salt aggregate within the organic phase was inflated into a single emulsion droplet, and finally double emulsions with a controlled multicore architecture were formed by adjusting the initial characteristics of the salt aggregates. Nevertheless, as the solubility of inorganic salts in the common organic solvents is quite low, and thus the generated osmotic pressure is not sufficient to counterbalance the Laplace pressure of the tiny water droplets formed within the organic oil phase, to the best of our knowledge the osmotically driven water/oil liquid-liquid phase separation has not been achieved in a homogeneous oil phase so far.

As mentioned in the Introduction section, the unique dual ionic and organic nature of ionic liquids provide them with a special affinity to inorganic salts and thus exceptional solubility of inorganic salts, in particular in the case of $\mathrm{C}_{n} \operatorname{vim}\left[\mathrm{Tf}_{2} \mathrm{~N}\right]-$ $\operatorname{LiTf}_{2} \mathrm{~N}$. Due to the multiple interactions between the $\mathrm{C}_{n} \mathrm{vim}$ $\left[\mathrm{Tf}_{2} \mathrm{~N}\right]$ ionic liquid and $\operatorname{LiTf}_{2} \mathrm{~N}$ salt, the solubility ratio of $\operatorname{LiTf}_{2} \mathrm{~N}$ in hydrophobic $\mathrm{C}_{n} \operatorname{vim}\left[\mathrm{Tf}_{2} \mathrm{~N}\right]$ oil reaches 0.5 , which much exceeds the saturated solubility ratio of $\mathrm{NaCl}$ in water $(0.12)$. We discovered that the salt species dissolved in the special ionic liquid oils could provide sufficient osmotic stress to draw water out of the water phase and into the oil phase, initiating water/oil liquid-liquid phase separation and spontaneously forming 
emulsion structures. In the case described by T. P. Russell and R. C. Hayward, the osmotically driven water/oil liquid-liquid phase takes place in a heterogeneous system through water transport between salt impurity aggregates and the bulky water phase, and thus the final structures of the osmotically formed emulsions are not sensitive to the kinetics, but instead only to the initial characteristics of the salt aggregates. ${ }^{\mathbf{4 3 4 4}}$ Completely different from this situation, the liquid-liquid phase separation osmotically driven by the molecule-level dissolved salts in oil described here could induce the formation of emulsions with numerous and diverse morphologies dependent on the adopted kinetic pathway using one system. Indeed, the remarkably high solubility of $\operatorname{LiTf}_{2} \mathrm{~N}$ in $\mathrm{C}_{n} \operatorname{vim}\left[\mathrm{Tf}_{2} \mathrm{~N}\right]$ oil provides an unprecedented degree and room for modulating the osmotic pressure, namely the thermodynamic driving force for phase separation. The facile variation in the alkyl length of the $\mathrm{C}_{n} \operatorname{vim}\left[\mathrm{Tf}_{2} \mathrm{~N}\right]$ molecule can easily tailor the kinetic barrier during phase separation. Additionally, the alteration of the salt concentration in the bulky water phase can control the direction of the phase separation process, and even the water taken-up in the formed heterogeneous emulsions can be drawn back into the bulky water phase to restore the initial homogeneous oil phase. These attributes indicate that based on the discovery of osmotically driven reversible water flow between aqueous and IL oil phases a new system could be developed towards highly kinetically controlled and even reconfigurable phase separation. As a result, the kinetic pathway of phase separation can be modulated in an unprecedented broad range, and arresting a variety of thermodynamically metastable structures induced is possible. More importantly, due to the extraordinary multiple types of molecular interactions involved in ILs, including van der Waals force, electrostatic force, hydrogen bonding, hydrophobic interaction, and $\pi-\pi$ interaction, one of the distinctive properties of ILs is their excellent solvency for a broad range of substances. ${ }^{25,26}$ ILs can even display peculiar solubility or dispersibility of these compounds or objects (e.g. biomass, carbon materials, or inorganic nanoparticles), whose processability is difficult or impossible using common organic solvents. This advantage implies that the $\mathrm{C}_{n} \operatorname{vim}\left[\mathrm{Tf}_{2} \mathrm{~N}\right]-\mathrm{LiTf}_{2} \mathrm{~N}$ system could be extended or utilized as a general carrier platform for phase separation, providing great opportunities for achieving the phase separation of a broad range of substances and correspondingly the creation of nanostructured functional materials.

\section{Conclusions}

In summary, by exploiting the unique solubility of inorganic salts in hydrophobic ionic liquids and thus the generated osmotic pressure, for the first time osmotically driven spontaneous water/oil phase separation (OPS) was achieved using the $\mathrm{C}_{n} \operatorname{vim}\left[\mathrm{Tf}_{2} \mathrm{~N}\right]-\mathrm{LiTf}_{2} \mathrm{~N}$ oil solution. Compared to the liquid-liquid phase separations reported so far, this osmotically driven phase separation process is characterized by the following distinct features. Firstly, owing to the extraordinary solubility of inorganic salts in ionic liquids as well as the easily tailorable molecular structure of $\mathrm{C}_{n} \operatorname{vim}\left[\mathrm{Tf}_{2} \mathrm{~N}\right]$ the thermodynamic (osmotic) driving force and kinetic barrier of water transport during the OPS process could be facilely modulated with unprecedented flexibility and range. Secondly, by simply adding salt into the aqueous phase, the OPS process is further finely tunable and even the phase separation direction could be adjustable. Surprisingly, it is found that the already phaseseparated heterogeneous state could even be reverted to restore the homogeneous oil phase by redrawing the water molecules taken up, indicating that the OPS is reconfigurable. Based on these attractive features, precise design and control of the speed and kinetic pathways of the phase separation process is possible, thus offering unlimited opportunities to facilely access and capture diverse thermodynamically metastable structures using one phase separation system. Importantly, the unique structure of ionic liquids allows the extraordinary solubility or dispersity of a broad range of substances in ionic liquids. Nevertheless, we found that after introduction of the various species the phase separation behavior of the $\mathrm{C}_{n}$ vim $\left[\mathrm{Tf}_{2} \mathrm{~N}\right]-\mathrm{LiTf}_{2} \mathrm{~N}$ oil system still remained without significant change, indicating that the $\mathrm{C}_{n} \operatorname{vim}\left[\mathrm{Tf}_{2} \mathrm{~N}\right]-\mathrm{LiTf}_{2} \mathrm{~N}$ system can serve as a general phase separation carrier platform for realizing the phase separation of various substances, especially those inaccessible using conventional methods. In this work, although only imidazolium-based ILs are explored for OPS, in principle our concept of osmotically driven oil/water phase separation could be extended to other ionic liquids, including pyridinium- and phosphonium-based ionic liquids. Therefore, with the simplicity, controllability, versatility, and potential scalability our findings would open up new avenues for efficiently producing oil/water phase separations, which could hold enormous potential for creating novel structures and chemical systems or in the development of new actuators or adaptive materials.

\section{Conflicts of interest}

There are no conflicts to declare.

\section{Acknowledgements}

The authors gratefully acknowledge the financial support from the NSF China (No. 21773135, 21473098, 21121004 and 21421064), MOST (2017YFA0204501 and 2013CB834502), and the Deutsche Forschungsgemeinschaft DFG (TRR61).

\section{Notes and references}

1 P. Atkins and J. de Paula, Atkins' Physical Chemistry, Oxford University Press, United Kingdom, 2014.

2 V. W. Sidel and A. K. Solomon, J. Gen. Physiol., 1957, 41, 243257.

3 E. L. Fiscus, Plant Physiol., 1975, 55, 917-922.

4 R. Munns, Aust. J. Plant Physiol., 1988, 15, 717-726.

5 S. E. Skilhagen, J. E. Dugstad and R. J. Aaberg, Desalination, 2008, 220, 476-482.

6 Y. C. Kim and M. Elimelech, J. Membr. Sci., 2013, 429, 330337. 
7 Y. Kim, M. Elimelech, H. K. Shon and S. Hong, J. Membr. Sci., 2014, 460, 206-212.

8 C. X. Guo, D. Zhao, Q. Zhao, P. Wang and X. Lu, Chem. Commun., 2014, 50, 7318-7732.

9 J. G. Park, S. H. Kim, S. Magkiriadou, T. M. Choi, Y. S. Kim and V. N. Manoharan, Angew. Chem., Int. Ed., 2014, 53, 2899-2903.

10 A. Peyret, E. Ibarboure, A. Tron, L. Beaute, R. Rust, O. Sandre, N. D. Mcclenaghan and S. Lecommandoux, Angew. Chem., Int. Ed., 2017, 56, 1566-1570.

11 J. J. F. Sleeboom, P. Voudouris, M. T. J. J. M. Punter, F. J. Aangenendt, D. Florea, P. V. D. Schoot and H. M. Wyss, Phys. Rev. Lett., 2017, 119, 98001.

12 (a) W. Zhang, A. Abbaspourrad, D. Chen, E. Campbell, H. Zhao, Y. Li, Q. Li and D. A. Weitz, Adv. Funct. Mater., 2017, 27, 1700975; (b) S.-H. Kim, J.-G. Park, T. M. Chio, V. N. Manoharan and D. A. Weitz, Nat. Commun., 2014, 5, 3068, DOI: $10.1038 /$ ncomms4068.

13 N. Garti, LWT-Food Sci. Technol., 1997, 30, 222-235.

14 J. A. Omotosho, Int. J. Pharm., 1990, 62, 81-84.

15 D. J. Mcclements and K. Demetriades, Crit. Rev. Food Sci. Nutr., 1998, 38, 511-536.

16 S. Iqbal, M. K. Baloch, G. Hameed and D. J. McClements, Food Res. Int., 2013, 54, 1613-1620.

17 S. Matsumoto, T. Inoue, M. Kohda and K. Ikura, J. Colloid Interface Sci., 1980, 77, 555-563.

18 H. L. Rosano, F. G. Gandolfo and J. D. P. Hidrot, Colloids Surf., A, 1998, 138, 109-121.

19 L. Wen and K. D. Papadopoulos, J. Colloid Interface Sci., 2001, 235, 398-404.

20 R. Mezzenga, B. M. Folme and E. Hughes, Langmuir, 2004, 20, 3574-3582.

21 J. Zhu and R. C. Hayward, J. Colloid Interface Sci., 2012, 365, 275-279.

22 N. V. Plechkova and K. R. Seddon, Chem. Soc. Rev., 2008, 37, 123-150.

23 M. V. Fedorov and A. A. Kornyshev, Chem. Rev., 2014, 114, 2978-3036.

24 R. Shi and Y. Wang, Sci. Rep., 2016, 6, 19644.

25 T. Welton, Chem. Rev., 1999, 99, 2071-2083.
26 R. D. Rogers and K. R. Seddon, Science, 2003, 302, 792-793. 27 A. B. Pereiro, J. M. M. Araujo, F. S. Oliveira, J. M. S. S. Esperanca, J. N. C. Lopes, I. M. Marrucho and L. P. N. Rebelo, J. Chem. Thermodyn., 2012, 55, 29-36.

28 V. L. Martins, B. G. Nicolau, S. M. Urahata, M. C. C. Ribeiro and R. M. Torresi, J. Phys. Chem. B, 2013, 117, 8782-8792.

29 M. Y. Lui, L. Crowhurst, J. P. Hallett, P. A. Hunt, H. Niedermeyer and T. Welton, Chem. Sci., 2011, 2, 14911496.

30 M. J. Monteiro, F. F. C. Bazito, L. J. A. Siqueira, M. C. C. Ribeiro and R. M. Torresi, J. Phys. Chem. B, 2008, 112, 2102-2109.

31 T. Nisisako and T. Torii, Lab Chip, 2008, 8, 287-293.

32 M. F. Haase, K. J. Stebe and D. Lee, Adv. Mater., 2015, 27, 7065-7071.

33 Y. Cheng, F. Zheng, J. Lu, L. Shang, Z. Xie, Y. Zhao, Y. Chen and Z. Gu, Adv. Mater., 2014, 26, 5184-5190.

34 M. F. Haase and J. Brujic, Angew. Chem., Int. Ed., 2014, 53, 11793-11797.

35 T. Fukushima, A. Kosaka, Y. Ishimura, T. Yamamoto, T. Takigawa, N. Ishii and T. Aida, Science, 2003, 300, 20722074.

36 G. T. Wei, Z. Yang, C. Y. Lee, H. Y. Yang and C. R. C. Wang, J. Am. Chem. Soc., 2004, 126, 5036-5037.

37 W. Ogihara, S. Washiro, H. Nakajima and H. Ohno, Electrochim. Acta, 2006, 51, 2614-2619.

38 C. X. Zhao and A. P. J. Middelberg, Angew. Chem., Int. Ed., 2009, 48, 7208-7211.

39 C. H. Choi, D. A. Weitz and C. S. Lee, Adv. Mater., 2013, 25, 2536-2541.

40 C. Solans and I. Sole, Curr. Opin. Colloid Interface Sci., 2012, 17, 246-254.

41 C. Solans, D. Morales and M. Homs, Curr. Opin. Colloid Interface Sci., 2016, 22, 88-93.

42 J. C. Lopez-Montilla, P. E. Herrera-Morales, S. Pandey and D. O. Shah, J. Dispersion Sci. Technol., 2002, 23, 219-268.

43 J. Bae, T. P. Russell and R. C. Hayward, Angew. Chem., Int. Ed., 2014, 53, 8240-8245.

44 X. Wang, X. Feng, G. Ma, D. Zhang, Y. Chai, M. Ge and L. Yao, Adv. Mater., 2017, 1605932. 